\title{
A Theoretical Study of Some Schiff Bases as 304 Stainless Steel Inhibitors in HCl Solution
}

\author{
Shuangkou Chen ${ }^{1,}$, Mingxin Xu ${ }^{1}$, Qian Tang ${ }^{1}$, Zhenning Yang ${ }^{2}$, Xiaoqing Tan $^{l}$, Bai He ${ }^{l}$, \\ Jiansheng Huang ${ }^{l}$ \\ ${ }^{1}$ College of Chemistry and Chem-engineering, Chongqing University of Science and Technology, \\ Chongqing 401331, China \\ ${ }^{2}$ Chongqing Changfeng Chemical Industrial Co., Ltd, Chongqing 401252,China \\ *E-mail: $\underline{\text { cskcn@yeah.net }}$
}

doi: $10.20964 / 2021.03 .06$

Received: 10 October 2020 / Accepted: 1 December 2020 / Published: 31 January 2021

For four types of molecular Schiff inhibitors, the relationships between their corrosion inhibition efficiencies (IE) and some specific molecular property-related parameters, are investigated by using three different theoretical ab initio methods: Hartree-Fock (HF), Möller-Plesset perturbation theory on the $2^{\text {nd }}$ order (MP2), and density functional theory (DFT). The parameters calculated include the energy of the highest occupied molecular orbital $\left(E_{\mathrm{HOMO}}\right)$, the energy of the lowest unoccupied molecular orbital ( $\left.E_{\mathrm{LumO}}\right)$, the energy difference between $E_{\mathrm{HOMO}}$ and $E_{\mathrm{LUMO}}(\Delta E)$, the dipole moment $(\mu)$, the electronegativity value $(x)$, the global hardness $(\eta)$, the softness $(\sigma)$, the fraction of transferred electrons between the molecular inhibitor and $\mathrm{Fe}(\Delta N)$, and Mulliken atomic charges $(\mathrm{Q})$. By using linear regression analysis, the relationships between $I E$ and each of these parameters are carefully studied with the purpose to find the most effective parameters for the best inhibition efficiency. As a result, the comparison between the three different theoretical methods shows that the Hartree Fock (HF) method, with the $6-31++\mathrm{G}(\mathrm{d}, \mathrm{p})$ basis set, gives the most accurate results. In addition, the corrosion inhibition performances of all four molecular Schiff inhibitors show a linear relationship with the $E_{\mathrm{HOMO}}, E_{\mathrm{LUMO}}$, $\Delta E, \mu, x, \eta, \sigma$, and $\Delta N$ parameters. In conclusion, this work provides a theoretical method by which it is possible to predict the corrosion inhibition performance of molecules with geometrical structures like the Schiff inhibitors.

Keywords: modeling studies; corrosion inhibition; Schiff base

$\underline{\text { FULL TEXT }}$ 
(C) 2021 The Authors. Published by ESG (www.electrochemsci.org). This article is an open access article distributed under the terms and conditions of the Creative Commons Attribution license (http://creativecommons.org/licenses/by/4.0/). 